University of Nebraska - Lincoln

DigitalCommons@University of Nebraska - Lincoln

Faculty Publications, Department of Psychology

Psychology, Department of

April 2007

\title{
A Latent Growth Curve Analysis of Prosocial Behavior Among Rural Adolescents
}

\author{
Gustavo Carlo \\ University of Nebraska-Lincoln, carlog@missouri.edu \\ Lisa J. Crockett \\ University of Nebraska-Lincoln, ecrockett1@unl.edu \\ Brandy A. Randall \\ North Dakota State University, Brandy.Randall@ndsu.edu \\ Scott C. Roesch \\ San Diego State University
}

Follow this and additional works at: https://digitalcommons.unl.edu/psychfacpub

Part of the Psychiatry and Psychology Commons

Carlo, Gustavo; Crockett, Lisa J.; Randall, Brandy A.; and Roesch, Scott C., "A Latent Growth Curve Analysis of Prosocial Behavior Among Rural Adolescents" (2007). Faculty Publications, Department of Psychology. 232.

https://digitalcommons.unl.edu/psychfacpub/232

This Article is brought to you for free and open access by the Psychology, Department of at DigitalCommons@University of Nebraska - Lincoln. It has been accepted for inclusion in Faculty Publications, Department of Psychology by an authorized administrator of DigitalCommons@University of Nebraska - Lincoln. 
Published in Journal of Research on Adolescence, 17:2 (April 2007)), pp. 301-324. Copyright (C) 2007, Society for Research on Adolescence; published by Blackwell Publishing. Used by permission. http://www.blackwellpublishing.com/journal.asp?ref=1050-8392

\title{
A Latent Growth Curve Analysis of Prosocial Behavior Among Rural Adolescents
}

\author{
Gustavo Carlo and Lisa J. Crockett \\ University of Nebraska-Lincoln \\ Brandy A. Randall \\ North Dakota State University \\ Scott C. Roesch \\ San Diego State University
}

\begin{abstract}
The present study was designed to investigate stability and changes in pro-social behavior and the parent and peer correlates of prosocial behavior in rural adolescents. Participants were from a rural, low SES community in the Eastern United States. The participants were in 7th, 8th, and 9th grades at Time 1 and 10th, 11th, and 12th grades at Time 4, and completed measures of prosocial behavior and quality of parent and peer relationships. Latent growth curve modeling revealed that despite moderate stability in individual differences in prosocial behavior and slight increases in quality of peer and parent relationships, level of prosocial behavior declined until late high school with a slight rebound in grade 12. Furthermore, increases in the quality of peer relationships predicted decreases in prosocial behavior for girls but not boys. Discussion focuses on continuity and change in prosocial behavior and the gender-based relations between quality of parent and peer relationships and prosocial behaviors in adolescence.
\end{abstract}

Corresponding author: Gustavo Carlo, Department of Psychology, University of NebraskaLincoln, 320 Burnett Hall, Lincoln, NE, 68588-0308. Email: gcarlo1@unl.edu 
Stereotypes and exaggerated beliefs about the "storm and stress" period of adolescence are so common that parents often remark about the fear of raising an adolescent child in the United States (see Garbarino, 1999; Pipher, 1994). Though the majority of adolescents do not engage in serious problem behaviors, negative stereotypes about adolescents are prevalent owing to media attention to tragic and dramatic national events (e.g., school shootings). Increasingly, however, researchers have addressed this stigma by examining positive social behaviors in adolescence (Lamborn, Mounts, Steinberg, \& Dornbusch, 1991; Offer, Ostrov, \& Howard, 1981; Scales, Benson, Leffert, \& Biyth, 2000; see Carlo, Fabes, Laible, \& Kupanoff, 1999; Fabes, Carlo, Kupanoff, \& Laible, 1999, for reviews). Furthermore, there has been increasing recognition of the need to examine positive social behaviors to further our understanding of social development (The Consortium on the School-Based Promotion of Social Competence, 1994).

\section{CHANGE AND STABILITY IN PROSOCIAL BEHAVIOR DURING ADOLESCENCE}

Prosocial behaviors are defined as behaviors primarily aimed at benefiting others (Eisenberg \& Fabes, 1998; Staub, 1978). They include behaviors such as sharing, comforting others, donating goods or money, volunteerism, and instrumental helping. The study of age-related changes in prosocial behaviors in adolescence is important given the individual and social changes that take place during this period. For example, adolescents experience significant gains in mobility and often negotiate for more independent decision making (Grotevant, 1998), which could provide opportunities to initiate specific forms of prosocial behaviors such as volunteerism and involvement in charitable organizations. Furthermore, there are increases in moral reasoning, empathy, and social understanding during adolescence, which are significantly associated with prosocial behaviors (Carlo, Eisenberg, \& Knight, 1992; Estrada, 1995). Finally, early adolescence presents opportunities for renegotiating existing relationships (e.g., with parents) and for developing new peer relationships that might impact (positively or negatively) prosocial behaviors (Berndt \& Ladd, 1989; Carlo, Raffaelli, Laible, \& Meyer, 1999; Youniss, 1980). Despite conceptual bases for expecting age-related changes in prosocial behaviors during adolescence, the evidence to date is mixed and inconsistent (Eisenberg \& Fabes, 1998; Fabes et al., 1999). Thus, there is further need to explore age-related changes in prosocial behaviors during adolescence.

Despite mixed findings regarding age-related changes in level of pro-social behavior during adolescence, there is evidence of stable, individual dif- 
ferences in prosocial behaviors (Eisenberg \& Fabes, 1998). For example, relatively stable individual differences in empathy have been reported in samples of children and adolescents (Davis \& Franzoi, 1991; Eisenberg et al., 1999). In one notable study, a middle to upper socioeconomic class sample of urban area children have been followed every 2 years from preschool into young adulthood (Eisenberg, Miller, Shell, McNalley, \& Shea, 1991; Eisenberg, Carlo, Murphy, \& Van Court, 1995; Eisenberg et al., 1999). The present study extends the prior findings by examining age-related trends in prosocial development within a relatively large community sample of rural adolescents and by examining parent and peer relationship correlates of these changes.

\section{THE ROLE OF PARENTING IN PROSOCIAL BEHAVIORS}

According to theorists, parents influence children's prosocial development by modeling and directing prosocial behaviors, by encouraging and rewarding appropriate behavior, and by creating an affective climate that encourages empathy and sympathy (Carlo et al., 1999; Grusec, 1991; Grusec \& Goodnow, 1994). For example, parents who encourage and maintain empathy and sympathy are believed to foster prosocial behaviors and a concern for others (Grusec, 1991; Hoffman, 1983). Furthermore, warm and supportive parents can promote prosocial development by nurturing interpersonal closeness and emotional expressiveness and by providing emotional support (Barnett, 1987; Baumrind, 1991; Maccoby \& Martin, 1983). Additionally, parents can assign adolescents household chores and responsibilities that address family needs and foster concern for the welfare of others (Grusec, Goodnow, \& Cohen, 1996).

To date, a growing body of studies using cross-sectional designs supports the theoretical assertion that parenting and family influences are linked to prosocial development (see Eisenberg \& Fabes, 1998). The available evidence indicates that supportive parenting is associated with pro-social behaviors (Carlo, Roesch, \& Melby, 1998; Eberly \& Montemayor, 1998, 1999; Eisenberg-Berg \& Mussen, 1978; Krevins \& Gibbs, 1996) and that authoritative parenting is linked to adolescents' social responsibility, social competence, and prosocial behavior (Baumrind, 1991; Dekovic \& Janssens, 1992; Gunnoe, Hetherington, \& Reiss, 1999; Lamborn et al., 1991; Steinberg, Lamborn, Darling, Mounts, \& Dornbusch, 1994). Taken together, these studies suggest that the quality of family relationships should be positively associated with prosocial behavior in adolescence. However, no research has examined whether changes in the quality of family relationships predicts changes in prosocial behaviors. For example, if renegotiation of 
the parent-adolescent relationship results in greater conflict and a less positive perception of the relationship, one might expect a decrease in the overall level of adolescents' prosocial behaviors. In contrast, if the greater selfdisclosure and intimacy characteristic of adolescents leads to more positive perceptions of the parent-adolescent relationship, one might expect an overall increase in prosocial behaviors.

\section{THE ROLE OF PEERS ON PROSOCIAL BEHAVIORS}

Other theorists (Csikszenthmihalyi \& Larson, 1984; Hartup, 1983; Larson \& Richards, 1991) have noted that peers are an important additional source of influence during adolescence. One of the major tasks of adolescence is the establishment and maintenance of peer networks (Brown, 1989). Much like parents and other family members, peers are socializing agents who may provide feedback, model behaviors, and offer emotional support. However, peers provide a unique context for social comparisons and for promoting behavior norms. Because adolescents view peers as being more like themselves than their parents are and because peer relationships tend to be symmetrical in social power (Hartup, 1983; Youniss, 1980), peers might serve as especially salient models of prosocial behaviors, as well as messengers of novel perspectives on moral issues and sources of social sanctions or rewards (Fabes et al., 1999). Of particular relevance to the present study is the possibility that the quality of peer relationships (e.g., perceptions of acceptance or rejection) influences the expression of prosocial behaviors. There is evidence that peer acceptance and status are linked to adolescents' prosocial behaviors (Schonert-Reichl, 1999; Wentzel \& Asher, 1995), and quality of peer relationships has been linked to adolescent moral development (Bukowski \& Sippola, 1996; Fur-man \& Masters, 1980). Extrapolating from these findings, positive changes in the quality of peer relationships during adolescence would be expected to predict positive changes in prosocial behaviors.

\section{GENDER DIFFERENCES IN PROSOCIAL BEHAVIORS}

Moral socialization theorists have postulated that there might be gender differences in prosocial behaviors, particularly during adolescence (Eisenberg $\&$ Fabes, 1998; Maccoby \& Jacklin, 1974). Such differences might be due to gender intensification and differential socialization pressures experienced by boys and girls during adolescence (see Fabes et al., 1999). Consistent with those notions, scholars have reported moderately strong gender differences in prosocial behaviors such that adolescent girls exhibit higher lev- 
els of prosocial traits and behaviors than do adolescent boys (Carlo, Koller, Eisenberg, Da Silva, \& Frohlich, 1996; Eisenberg et al., 1991). Given prior research showing that adolescent girls tend to have fewer and more intimate relationships with peers than adolescent boys (e.g., Crockett, Losoff, \& Petersen, 1984; Rice \& Mulkeen, 1995) and that parents have more open communication and more involvement with girls and monitor them more closely than boys (Carlo et al., 1999; Lefkowitz, Boone, Sigman, \& Kit-fong Au, 2002; Richards, Miller, O'Donnell, Wasserman, \& Colder, 2004), the relations between quality of peer and parent relationships and prosocial behaviors might be different for adolescent boys and girls. However, no studies exist that directly examine this issue. Therefore, we explored the relations between quality of peer and parent relationships and prosocial behaviors separately for adolescent boys and girls.

\section{HYPOTHESES}

In summary, the goal of this study was to investigate age-related changes in level of prosocial behaviors in a rural adolescent sample and the possible role of parent and peer relationship quality in these changes. Based on the mixed findings of prior research, it was difficult to predict whether there would be increases or decreases in level of prosocial behaviors between early and middle adolescence. However, individual differences in prosocial behaviors were expected to be relatively stable across that time period. The quality of peer and parent-adolescent relationships were expected to positively predict prosocial behaviors, and changes in parent and peer relationship quality were expected to be positively associated with changes in prosocial behaviors. Furthermore, girls were expected to report more prosocial behaviors than boys. However, given the lack of prior research on gender differences in the correlates of prosocial behaviors in adolescence, we made no specific predictions regarding the gender-specific relations between quality of parent and peer relationships and changes in prosocial behaviors across these years.

\section{METHOD}

\section{Participants and Context}

The sample was recruited from schools serving a geographically contained rural area in the Eastern United States (Vicary, 1991). The area was composed of small boroughs and townships located approximately 3 hours from the nearest urban center. Lack of public transportation further isolated the com- 
munity from neighboring towns. According to census data, the residents were middle to low income and primarily White (approximately 96\%). School census data for 1980 (the last census before the study began) indicated that $69 \%$ of the adults had a high school education or less, the median household income was $\$ 14,500$, and the primary occupational categories were laborers and technical/clerical. Approximately $12 \%$ of families had incomes below the poverty level. Although there was heterogeneity with respect to socioeconomic status, the community as a whole was considered disadvantaged.

The target population of the original 5-year, longitudinal study included all junior high school students in the district. The district had two junior high schools, each containing grades 7-9, and a single high school. All students in grades 7,8 , and 9 at the outset were invited to participate: participants from these cohorts were surveyed annually through 12 th grade. At Time 1, students in the sample had a mean age of 13.34 years $(S D=.97)$ and most were White and of European American descent. The mean of their mother's highest level of education was $3.13(S D=1.00)$ using a seven-point scale ranging from 1 = grade school only to 7 = beyond college (a score of 3 was "completed high school").

In the first year of the study (Time 1), 313 girls and 344 boys participated, over $90 \%$ of the target population (Vicary, 1991). There were 286 girls and 304 boys present at both Times 1 and 2, 249 girls and 267 boys present at Times 2 and 3, and 225 girls and 231 boys present at both Time 3 and Time 4. Time 5 data was not used in the present study because most of the oldest grade cohort had graduated. The cohort-sequential longitudinal design allowed us to examine prosocial development across the three-grade-cohorts from junior through senior high school. Students who were absent on the day of the survey, who refused to participate, or whose parents refused consent were excluded from data collection. However, students who were absent at one time point were not excluded from future data collection, so nonparticipation in 1 year did not necessarily mean permanent attrition. Participants may have been absent in a given year of the study for a multitude of reasons, including dropping out of school or moving (permanent attrition), as well as being absent from school on the day of the study (temporary attrition). New participants from the designated cohorts were added to maximize representativeness of the sample in each wave (see Vicary, 1991).

\section{Procedure}

Data were collected through written survey questionnaires administered during the regular school day by project staff in the fall of each school year. The 
survey was administered to small groups of students in quiet rooms (e.g., library) in the schools but outside of class. Boys and girls were separated during survey administration. To maintain privacy and confidentiality, teachers and school administrators were excluded from all aspects of the surveying process and no names were used on the survey forms. Numeric codes were used to link each student's data from year to year. Passive consent (which was requested by the schools) was used as approved by the School District and the Institutional Review Board.

\section{Measures}

Quality of parent-child and peer relationships. Perceptions of the quality of relationships with peers and parents, respectively, were assessed using two subscales from the Self-image Questionnaire for Young Adolescents (SIQYA; Petersen, Schulenberg, Abramowitz, Offer, \& Jarcho, 1984). Parent-child relationships were assessed with the Family Relations subscale, which included 17 items (sample items, "I can count on my parents most of the time" and "Most of the time my parents are satisfied with me"). Peer relationships were assessed with the Peer Relations subscale, which included 10 items (sample items, "I do not have a particularly difficult time making friends" and "I usually feel out of place at picnics and parties"). Responses ranged from $1=$ very strongly agree to $6=$ very strongly disagree. Scale scores were means computed so that a higher score indicated more positive peer or parent relationships. Cronbach's $\alpha$ coefficients for the parent relationships scale ranged from .86 to .90 (17 items) across the four assessment times. Cronbach's $\alpha$ coefficients for the peer relationships scale ranged from .79 to .85 (10 items). Reliability and validity evidence for the SIQYA scales has been previously documented (e.g., Petersen et al., 1984; Seginer \& Somech, 2000).

Prosocial behavior. The Primary Prevention Awareness, Attitudes and Usage Scale (PPAAUS; Swisher, Shute, \& Bibeau, 1984) was used to assess frequency of prosocial behaviors. The PPAAUS includes several subscales assessing a variety of prosocial and antisocial behaviors. For the present study, the six items assessing prosocial behavior were used. The items tapped into a range of prosocial behaviors including volunteering, helping, raising or donating money, sharing, and doing favors for others. Two sample items were, "Did someone a favor or lent someone money" and "Helped a friend with a problem." Responses could range from $1=$ never happened to $5=$ happens almost every day. (At Time 3, the response scale was extended to six points. Thus, in order to make the data comparable across the time points, the six- 
point scale used at Times 3 and 4 was receded to match the original five-point scale by collapsing the scale responses of two and three into a value of two). The mean of these items was computed for each subject, such that a high score on the prosocial behavior scale indicated a higher frequency of prosocial acts. Cronbach's a coefficients ranged from .61 to .70 (six items). Adequate psychometric properties of the PPAAUS subscales were documented previously (e.g., Carlo \& Randall, 2002; Crockett \& Bingham, 2000; Jacobson \& Crockett, 2000).

\section{Attrition Analyses and Missing Data Analysis}

Possible effects of attrition were examined with $t$-tests that compared Time 1 scores for participants who were retained at Time 4 with those were absent. Those who remained in the sample tended to be younger $(M=13.20, S D=$ $.88)$ than those who dropped out $(M=13.76, S D=1.10), t(652)=-5.83, p$ $<.001, d=.56$. Those who were retained also had mothers with significantly higher levels of education $(M=3.18, S D=.98)$ than those who dropped out $(M=2.96, S D=1.05), t(616)=2.40, p<.05, d=.22$. Participants who were retained reported more positive family relationships $(M=4.44, S D=.75)$ and peer relationships $(M=4.51, S D=.73)$ than those who dropped out (family relationships $M=4.27, S D=.75$; peer relationships $M=4.36, S D=.76$ ), $t(651)=2.54, p<.05, d=.23$ and $t(652)=2.26, p<.05, d=.20$, respectively. Those who were retained reported more prosocial behaviors $(M=3.21$, $S D=.66)$ than those who were not retained $(M=3.05, S D=.60), t(641)=$ $2.63, p<.01, d=.25$. Thus, the analyses revealed evidence that the final sample was somewhat better adjusted than the original sample.

An additional series of $t$-test analyses was conducted to compare differences between participants who were there at Time 1 and those who were added at Time 2 . The results indicated that those who were added to the study had mothers with less education $(M=2.68, S D=.87)$ than those who were present at Time $1(M=3.23, S D=1.02), t(595)=3.24, p<.001, d=.58$. Those who were added also reported less positive family $(M=4.16, S D=$ $.66)$ and peer relationships $(M=4.34, S D=.71)$ than those present at Time 1 (family relationships $M=4.55, S D=.78$; peer relationships $M=4.59, S D=$ $.76), t(623)=3.08, p<.01, d=.54$ and $t(625)=2.02, p<.05, d=.34$, respectively. Participants added at Time 2 exhibited less prosocial behaviors $(M=$ $2.81, S D=.67)$ than those who were present at Time $1(M=3.14, S D=.67)$, $t(623)=2.96, p<.01, d=.49$. These analyses showed that the added participants were somewhat less well-adjusted than the original sample.

For the original data set, five primary missing data patterns were observed: (a) 34 participants were missing only Time 1 data, (b) 16 participants were 
missing only Time 2 data, (c) 49 participants were missing only Time 3 data, (d) 67 participants were missing only Time 4 data, and (e) 47 participants were missing both Times 3 and 4 data. To account for missing data, the fullinformation maximum likelihood method for co-variance structure modeling with longitudinal data was used (see Raykov, 2005). Recent studies (e.g., Collins, Schafer, \& Kam, 2001; Enders, 2001; Schafer \& Graham, 2002) have shown that this method has desirable statistical properties (e.g., low estimator bias) even with mild departures from multivariate normality and data that is assumed to be missing at random.

\section{RESULTS}

\section{Descriptive Analyses and Stability Coefficients}

Means and standard deviations at each time point for the main study variables are presented in Table 1. The stability coefficients for prosocial behaviors, parent relationships, and peer relationships were all significant (both practically and statistically) and positive (see Table 2). Correlations across the four time-points were $(r$ 's $=.50-.69)$ for parent relationships, $(r$ 's $=.52-.69)$ for peer relationships, and $(r$ 's $=.44-.62)$ for prosocial behaviors. Bivariate correlations between prosocial behaviors, parent relationships, and peer relationships were all positive and significant within and across time.

\section{Latent Growth Curve Analysis (LGCA)}

To examine the longitudinal relations among the target study variables a LGCA for cohort-sequential (or accelerated) designs was employed (see Duncan, Duncan, Strycker, Li, \& Alpert, 1999). The three grade groups (grades 7 , 8 , and 9 at Time 1) or cohorts have temporally overlapping periods of measurement across the 4-year assessment period. Using this design one can approximate a six grade (or year) longitudinal design, from grades 7-12. LGCA defines two latent factors (the intercept and slope) from a structural equation modeling framework (see e.g., Curran, 2000;

Duncan, Duncan, Alpert, \& Hops, 1997). In the current study the intercepts and slopes represented the growth trajectories of prosocial behaviors, parent relationships, and peer relationships, respectively. In each case, the intercept was centered relative to scores at the first time-point so that the intercept represents the initial status of the growth curve. The slope represents the functional form (i.e., linear or nonlinear) of the growth trajectory across the time-points. Individual variability around the intercept and slope (i.e., random effects) can also be assessed from this framework. 


\section{TABLE 1}

Means and Standard Deviations (SDS) for Prosocial Behaviors, Quality of Parent Relationships, and Quality of Peer Relationships by Cohort

\begin{tabular}{|c|c|c|c|c|c|c|}
\hline \multirow[b]{2}{*}{ Variable and Time of Measurement } & \multicolumn{2}{|c|}{ Cohort $7^{a}$} & \multicolumn{2}{|c|}{ Cohort $8^{b}$} & \multicolumn{2}{|c|}{ Cohort $9^{c}$} \\
\hline & $M$ & $S D$ & $M$ & $S D$ & $M$ & $S D$ \\
\hline Parent relationships $\mathrm{T} 1$ & 4.36 & .57 & 4.42 & .73 & 4.34 & .76 \\
\hline Parent relationships $\mathrm{T} 2$ & 4.44 & .64 & 4.53 & .76 & 4.50 & .73 \\
\hline Parent relationships T3 & 4.40 & .70 & 4.50 & .74 & 4.40 & .70 \\
\hline Parent relationships $\mathrm{T} 4$ & 4.42 & .77 & 4.48 & .68 & 4.54 & .71 \\
\hline Peer relationships $\mathrm{T} 1$ & 4.34 & .75 & 4.53 & .67 & 4.54 & .72 \\
\hline Peer relationships T2 & 4.48 & .81 & 4.63 & .66 & 4.60 & .72 \\
\hline Peer relationships T3 & 4.48 & .74 & 4.72 & .62 & 4.65 & .62 \\
\hline Peer relationships T4 & 4.65 & .69 & 4.73 & .62 & 4.73 & .65 \\
\hline Prosocial behavior T1 & 3.13 & .57 & 3.20 & .65 & 3.19 & .64 \\
\hline Prosocial behavior T2 & 3.03 & .63 & 3.18 & .64 & 3.15 & .62 \\
\hline Prosocial behavior T3 & 2.79 & .61 & 2.89 & .50 & 2.89 & .47 \\
\hline Prosocial behavior T4 & 2.90 & .57 & 2.90 & .49 & 3.03 & .52 \\
\hline
\end{tabular}

${ }^{\mathrm{a}} N=226$.

${ }^{\mathrm{b}} N=255$.

${ }^{\mathrm{c}} N=242$.

Note. T1, Time 1; T2, Time 2; T3, Time 3; T4, Time 4.

A series of models was tested in the following sequence (see Table 3). First, to determine the developmental growth trajectories and variability around these trajectories an unconditional linear growth was initially fit to each primary variable over time (Models la-c in Table 3 are also referred to as fixed time scores models). In addition, models freely estimating the time scores for each unconditional growth model were also tested to determine if significant nonlinearities emerged for the target study variables across time (Models 2ac). Next, a conditional growth model was tested predicting the latent intercept and slope for parent relationships, peer relationships, and prosocial behaviors, respectively, with gender included as a predictor (Models $3 \mathrm{a}-\mathrm{c}$ ). Finally a predictive model was tested with (a) the latent intercept factors of both the parent and peer relationship models predicting the latent intercept factors for the prosocial behaviors model and (b) the latent slopes of both the parent and peer relationship models predicting the latent slope factor for the prosocial behaviors model. All models were tested in the overall sample as well as in each gender group (Models $4 \mathrm{a}-\mathrm{c}$ ). ${ }^{1}$ 


\section{TABLE 2}

Intel-correlations Among Quality of Parent Relationships, Quality of Peer Relations, and Prosocial Behaviors

\begin{tabular}{lccccccccccc}
\hline & 1 & 2 & 3 & 4 & 5 & 6 & 7 & 8 & 9 & 10 & 11 \\
\hline 1. Parent relationships T1 & - & & & & & & & & & \\
2. Parent relationships T2 & $.65^{* *}$ & - & & & & & & & & \\
3. Parent relationships T3 & $.56^{* * *}$ & $.69^{* *}$ & - & & & & & & & \\
4. Parent relationships T4 & $.50^{* *}$ & $.61^{* *}$ & $.68^{* *}$ & - & & & & & & \\
5. Peer relationships T1 & $.37^{* *}$ & $.35^{* *}$ & $.25^{* *}$ & $.24^{* *}$ & - & & & & & \\
6. Peer relationships T2 & $.29^{* *}$ & $.46^{* *}$ & $.32^{* *}$ & $.29^{* *}$ & $.64^{* *}$ & - & & & & \\
7. Peer relationships T3 & $.28^{* *}$ & $.37^{* *}$ & $.42^{* *}$ & $.33^{* *}$ & $.52^{* *}$ & $.63^{* *}$ & - & & & \\
8. Peer relationships T4 & $.28^{* *}$ & $.35^{* *}$ & $.34^{* *}$ & $.47^{* *}$ & $.54^{* *}$ & $.63^{* *}$ & $.69^{* *}$ & - & & & \\
9. Prosocial behavior T1 & $.13^{*}$ & $.13^{*}$ & $.11^{*}$ & $.12^{*}$ & $.20^{* *}$ & $.15^{* *}$ & $.15^{* *}$ & $.17^{* *}$ & - & & \\
10. Prosocial behavior T2 & $.16^{* *}$ & $.26^{* *}$ & $.14^{*}$ & $.14^{*}$ & $.21^{* *}$ & $.26^{* *}$ & $.23^{* *}$ & $.23^{* *}$ & $.55^{* *}$ & - & \\
11. Prosocial behavior T3 & $.14^{*}$ & $.20^{* *}$ & $.19^{* *}$ & $.12^{*}$ & $.15^{* *}$ & $.15^{*}$ & $.20^{* *}$ & $.16^{*}$ & $.45^{* *}$ & $.58^{* *}$ & - \\
12. Prosocial behavior T4 & $.14^{*}$ & $.13^{*}$ & $.10^{*}$ & $.15^{* *}$ & $.12^{* *}$ & $.12^{*}$ & $.13^{*}$ & $.20^{* *}$ & $.44^{* *}$ & $.54^{* *}$ & $.62^{* *}$ \\
\hline
\end{tabular}

Note. Stability coefficients are in bold.

$* p<.01 ; * * p<.001$.

\section{TABLE 3}

Fit Indices for all LGCA Models

\begin{tabular}{lrrrr}
\hline Model & $\chi^{2}$ & df & CFI & SRMR \\
\hline 1a. Unconditional linear growth model-parent relationships & 56.9 & 21 & .98 & .06 \\
1b. Unconditional linear growth model-peer relationships & 47.9 & 21 & .98 & .06 \\
1c. Unconditional linear growth model-prosocial behavior & 195.3 & 21 & .94 & .08 \\
2a. Free time scores growth model-parent relationships & 47.5 & 17 & .98 & .05 \\
2b. Free time scores growth model-peer relationships & 45.7 & 17 & .98 & .06 \\
2c. Free time scores growth model-prosocial behavior & 165.0 & 17 & .94 & .07 \\
3a. Conditional growth model with covariates-parent relationships & 74.3 & 31 & .98 & .06 \\
3b. Conditional growth model with covariates-peer relationships & 51.3 & 31 & .98 & .06 \\
3c. Conditional growth model with covariates-prosocial behavior & 213.8 & 31 & .93 & .09 \\
4a. Overall predictive model & 699.8 & 198 & .90 & .07 \\
4b. Predictive model for males & 461.2 & 198 & .91 & .07 \\
4c. Predictive model for females & 456.7 & 198 & .91 & .08 \\
\hline
\end{tabular}

Note. CFI, comparative fit index; SRMR, standardized root mean square residual; LGCA, latent growth curve analysis. 


\section{Preliminary Model Testing Considerations}

We used the maximum likelihood estimation procedure in EQS for Windows 6.1 to test the three sets of models. Overall model fit was determined using the $\chi^{2}$ likelihood ratio test, the standardized root mean square residual (SRMR), and the comparative fit index (CFI). Because the $\chi^{2}$ likelihood ratio test is sensitive to sample size, the SRMR and CFI were used as primary indices of individual model fit, with SRMR values $<.08$ indicating reasonable model fit and CFI values greater than .90 indicating reasonable model fit. $^{2}$ Additionally, the $\chi^{2}$ difference test $\left(\Delta \chi^{2}\right)$ was used to statistically compare nested models. Fit indices for all models are presented in Table 3 .

\section{Unconditional Linear Growth Models}

The unconditional linear growth model for parent relationships fit the data well (Model 1a). Both the intercept $(M=4.31, t=141.26)$ and slope $(b=$ $.018, t=2.02)$ latent factors differed significantly from $0(p$ 's $<.05) .{ }^{3}$ Significant individual variability was found for both the intercept $\left(\sigma^{2}=.48, t=7.40\right.$, $p<.001)$ and slope $\left(\sigma^{2}=.01, t=2.48, p<.05\right)$. The linear growth model estimating the time scores also fit the data well (Model 2a). The fixed time score linear growth model did not significantly differ from the freely estimated time score model, $\Delta \chi^{2}(4)=9.4, p>.05$. Thus, quality of parent relationship increased slightly from early to middle adolescence.

The unconditional linear growth model for peer relationships fit the data well (Model 1b). Both the intercept $(M=4.42, t=141.66)$ and slope $(b=.071$, $t=8.71)$ latent factors differed significantly from $0(p ’ s<.05)$. Significant

${ }^{1}$ Autoregressive models with cross-lagged relations were also examined individually and within the context of autoregressive latent trajectory models (see Bollen \& Curran, 2004; Curran \& Bollen, 2001). Statistically significant and strong autoregressive estimates were found between all time-points, as also displayed by the correlations. However, no significant crosslagged effects were found.

2 The more stringent cutoff values for indices of descriptive model fit suggested by $\mathrm{Hu}$ and Bentler (1999) were not used in the current study due to the complexity of the models being tested. Recent Monte Carlo research and commentary (Fan \& Sivo, 2005; Marsh, Hau, \& Wen, 2004) has suggested that the models used by $\mathrm{Hu}$ and Bentler were overly simplistic and thus the "rules" derived may not be applicable to more complex model testing situations.

${ }^{3}$ The statistical significance of the intercept term in the unconditional model is not substantively interesting because the value of 0 for the target study variables is not meaningful. This test is presented here for completeness. 
individual variability was found for both the intercept $\left(\sigma^{2}=.47, t=7.61, p\right.$ $<.001)$ and slope $\left(\sigma^{2}=.01, t=3.56, p<.01\right)$. The linear growth model estimating the time scores also fit the data well (Model 2b). However, the fixed time score linear growth model did not significantly differ from the freely estimated time score model, $\Delta \chi^{2}(4)=2.20, p>.05$. Thus, quality of peer relationships increased slightly during this age period.

The unconditional linear growth model for prosocial behavior fit the data reasonably well (Model 1c). Both the intercept $(M=3.19, t=121.63)$ and slope $(b=-.061, t=-3.65)$ latent factors differed significantly from 0 $(p$ 's $<.05)$. Significant individual variability was found for both the intercept $\left(\sigma^{2}=.21, t=7.02, p<.001\right)$ and slope $\left(\sigma^{2}=.03, t=5.02, p<.001\right)$. The linear growth model estimating the time scores also fit the data reasonably well (Model 2c). The fixed time score linear growth model, however, fit significantly worse than the freely estimated time score model, $\Delta \chi^{2}(4)=30.3, p<$ .001 . The estimated means using the freely estimated time score model were: grade $7=3.21$, grade $8=3.13$, grade $9=3.08$, grade $10=2.98$, grade 11 $=2.89$, grade $12=2.97$. Thus, prosocial behavior gradually decreased until grade 11 after which it increased marginally.

\section{Conditional Growth Models with Gender}

The conditional linear growth model for parent relationships using gender as a predictor of the latent intercept and slope factors fit the data well (Table 3, Model 3a). However, gender did not significantly predict the intercept $(b=$ $\left..04, R^{2}=.001, t=.55, p>.05\right)$ or the slope $\left(b=.02, R^{2}=.005, t=.83, p>\right.$ $.05)$. The conditional linear growth model for peer relationships using gender as a predictor of the latent intercept and slope factors also fit the data well (Model 3b). Again, gender did not significantly predict the intercept $(b=.02$, $\left.R^{2}=.001, t=.27, p>.05\right)$ or the slope $\left(b=.03, \mathrm{R}^{2}=.001, t=.39, p>.05\right)$. For prosocial behavior a different pattern was observed. The conditional linear growth model for prosocial behaviors using gender as a predictor fit the data reasonably well (Model 3c). ${ }^{4}$ However, gender was significantly associated with both the intercept $\left(b=-.45, R^{2}=.13, t=-8.17, p<.001\right)$ and the slope $\left(b=.04, R^{2}=.06, t=2.60, p<.05\right)$. Specifically, girls started out with significantly higher prosocial behaviors at Time 1 (grade 7) than boys did, and over time boys' prosocial behaviors declined more rapidly than girls' did.

${ }^{4}$ Because (a) of the nonlinear relationship for prosocial behaviors across time was limited to the last time-point and (b) the unconditional linear growth model also fit the data well, predictive models used the latter as the primary outcome variable. 


\section{Predicting Prosocial Behaviors Factors from Parent and Peer Relationship Factors}

A final conditional growth model was tested predicting the latent intercept and slope for prosocial behaviors from the latent intercept and slope of both parental and peer relationships (Table 3). This model fit the data reasonably well overall (Model 4a) and in each gender group (Models 4b, be). In the model for the overall sample, the intercept factors for parent-child relationships $(b=.09, t=2.18, p<.05)$ and peer relationships $(b=.20, t=4.77, p<$ $.001)$ were associated with the intercept factor for prosocial behaviors $\left(R^{2}=\right.$ .08). Those participants who started out high on parent and peer relationships also started out high in prosocial behaviors. Additionally, the slope factor for peer relationships $(b=.29, t=3.58, p<.01)$, but not parental relationships $(b=.02, t=1.30, p>.05)$, was significantly associated with the slope factor for prosocial behaviors $\left(R^{2}=.12\right)$. Steeper increases in peer relationships were associated with steeper decreases in prosocial behaviors across time. Mothers' education $(b=.07, t=2.03, p<.05)$, but not child's age $(b=.01, t$ $=.13, p>.05)$, was significantly associated with the slope factor for prosocial behaviors. ${ }^{5}$

In the model for boys, the intercept factor for parental relationships $(b$ $=.30, t=4.64, p<.001)$, but not peer relationships $(b=-.02, t=-.25, p>$ $.05)$, was associated with the intercept factor for prosocial behaviors $\left(R^{2}=\right.$ $.05)$. Boys who started out with relatively high scores on parent relationships also started out with higher scores on prosocial behaviors. However, neither the slope factor for parent relationships $(b=.17, t=1.52, p<.05)$ nor peer relationships $(b=.09, t=.94, p>.05)$ was significantly associated with the slope factor for prosocial behaviors $\left(R^{2}=.09\right)$. Mothers' education $(b=.09$, $t=2.21, p<.05)$, but not child's age $(b=.02, t=.85, p>.05)$, was significantly associated with the slope factor for prosocial behaviors.

In the model for girls, the intercept factors for both parental relationships $(b=.18, t=2.82, p<.01)$ and peer relationships $(b=.13, t=2.01, p<.05)$ were associated with the intercept factor for prosocial behaviors $\left(R^{2}=.11\right)$. Girls who started out relatively high on parent and peer relationships also started out relatively high on prosocial behaviors. Additionally, the slope fac-

${ }^{5}$ A model examining the relations between the latent intercept factors for both parental and peer relationships with the latent slope factor for prosocial behaviors did not result in any significant associations (all $p$ 's $>.05$ ). 
tor for peer relationships $(b=.41, t=2.42, p<.05)$, but not parental relationships $(b=.04, t=.37, p>.05)$, was significantly associated with the slope factor for prosocial behaviors $\left(R^{2}=.11\right)$. For girls, steeper increases in peer relationships were associated with steeper decreases in prosocial behaviors across time. Mothers' education ( $b=.06, t=2.21, p<.05)$, but not child's age ( $b=.02, t=.45, p>.05)$, was significantly associated with the slope factor for prosocial behaviors.

\section{DISCUSSION}

To our knowledge, this is the first study to use LGCA to examine changes in prosocial behaviors across adolescence. A second goal was to examine quality of parent and peer relationships as predictors of prosocial behaviors during adolescence. The results suggest that there was an overall decline in prosocial behaviors until grade 11 (particularly for boys), after which prosocial behaviors rebounded slightly. In contrast, quality of peer and parent relationships increased slightly during this same period. For girls, decreases in prosocial behaviors were associated with increases in the quality of peer relationships. However, for boys, changes in level of prosocial behavior were not associated with changes in either parent-child or peer relationships. Furthermore, there was evidence of relative stability in individual differences in prosocial behaviors from early to middle adolescence.

\section{Age-Related Trends in Prosocial Behaviors}

Longitudinal analyses revealed an overall decline in mean level of pro-social behaviors across early to middle adolescence with a slight rebound in 12th grade. Given conceptual reasons to expect that prosocial behaviors continue to increase during adolescence (see Eisenberg \& Fabes, 1998), the reported decline in prosocial behaviors was somewhat surprising. However, as noted earlier, the findings regarding age trends in prosocial behaviors during adolescence are somewhat less clear than age trends in prosocial behaviors during childhood. Eisenberg and Fabes (1998) and Fabes et al. (1999) noted a relative dearth of research on age trends in prosocial behaviors in adolescence. Also, these meta-analytic reviews of the existing literature have yielded evidence that the relations between age and prosocial behaviors vary as a function of the characteristics of studies (e.g., study design, measures). The slight rebound (positive trajectory) between 11 th and 12th grade suggests that pro- 
social behaviors might begin to increase by the end of high school; further research is needed to investigate whether this rebound is temporary or whether it continues into early adulthood.

Of particular interest is the fact that that the overall decrease in pro-social behavior was due mostly to a decrease in prosocial behaviors among boys. This finding could reflect gender-specific socialization pressures encouraging adolescent boys to inhibit prosocial tendencies (such as expressing sadness and sympathy) which are inconsistent with the strong masculine stereotype (e.g.. Carlo et al., 1999). Gender intensification theorists have noted that gender stereotypes appear to strengthen during adolescence, and there is evidence from meta-analytic reviews that gender differences in prosocial behaviors are strongest during adolescence (Fabes et al., 1999). Moreover, secondary school brings increasing academic (as well as athletic and relationship) demands that could orient adolescents towards competitiveness and individual-based achievement, and the social contextual changes during adolescence (e.g., new and larger schools and changing support networks) might result in increased levels of stress, which in turn, could precipitate a decline in prosocial behaviors (Carlo et al., 1999). Alternatively, the decline in prosocial behaviors might reflect adolescent boys' increasing attention to their own needs and concerns. For example, prior studies have documented an increase in self-focused modes of prosocial moral reasoning during adolescence and that boys score higher than girls in this type of prosocial moral reasoning, which is associated negatively with prosocial behaviors (Carlo et al., 1996; Eisenberg et al., 1995). Taken together, these different forces might result in decreases in prosocial behaviors during adolescence particularly among boys.

\section{Relations Between Parent-Child and Peer Relationship Quality and Pro- social Behaviors}

We examined whether changes in the quality of either parent-child or peer relationships predicted changes in adolescents' prosocial behaviors. The findings showed that increases in the quality of peer relationships were associated with decreases in prosocial behaviors in girls, although not in boys. Why an increase in quality of relationships with peers is associated with decreases in prosocial behaviors among girls is not clear. However, prior researchers have shown that girls report more relational aggression (i.e., hurtful behaviors conducted by manipulating relationships with others) than boys during adolescence (Crick \& Gropeter, 1995). Perhaps the new and emerging relationships with peers (including intimate and romantic relationships) present new chal- 
lenges and demands in the peer context that reduce girls' expression of prosocial behaviors. Clearly, more research will be needed to understand gender differences in the correlates of prosocial behaviors during adolescence but the findings suggest the need to further study the notion that there might be gender-based pathways of prosocial development.

\section{Stability of Individual Differences in Prosocial Behaviors}

Another striking finding of the present study was the stability of individual differences in prosocial behaviors in adolescence as evidenced by the relatively high correlations across time. Although scholarly debate continues about whether there is an altruistic personality, the present findings add to mounting evidence that there are individuals who exhibit prosocial tendencies across time and across situations (Davis \& Franzoi, 1991; Eisenberg et al., 1999). The high stability coefficients might be reflective of stable personality characteristics, or stable environments, or a combination of both. There is evidence that there are relatively stable personality characteristics (e.g., empathy) related to prosocial behaviors across this age period (Davis \& Franzoi, 1991; Eisenberg et al., 1999) and that empathy has a relatively high heritability coefficient which might be temperamentally based (Carlo et al., 1998; see Eisenberg \& Fabes, 1998). Indeed, the stability coefficients for prosocial behavior were relatively strong and comparable to stability coefficients found in studies of aggression (Cairns, Cairns, Neckerman, Ferguson, \& Gariepy, 1989; Huesmann, Eron, Lefkowitz, \& Walder, 1984; Pulkinnen \& Pitkanen, 1993). However, in contrast to the studies on the stability of aggression, stability coefficients for prosocial behaviors were similar for boys and girls. Given the accumulating evidence that early patterns of aggression can predict adult outcomes (e.g., Huesmann et al., 1984; Pulkinnen \& Pitkanen, 1993), it would be of interest to examine whether early patterns of prosocial behavior similarly predict adult adjustment.

Consistent with prior research (Beutel \& Johnson, 2004; Fabes et al., 1999; Froming, Nasby, \& McNamus, 1998), girls consistently reported higher levels of prosocial behavior than boys across adolescence. These findings accord with gender socialization theories (e.g., Gilligan, 1982) that posit different developmental trajectories for boys and girls with regard to moral behaviors. Gender differences in prosocial behaviors might be expected to intensify during adolescence as a result of the differential direct feedback that boys and girls receive from socialization agents (e.g., Hill \& Lynch, 1983). 


\section{Study Limitations}

Despite the potential importance of the present findings for furthering our understanding of prosocial development during adolescence, some caution is needed in interpreting the results. First, this study focused on a sample of rural, low to middle SES adolescents followed from the mid- to late-1980s, so results might not apply to other (e.g., urban) populations. However, there is no reason to assume that prosocial behaviors and support from parents and peers have changed dramatically since the 1980s. Furthermore, researchers suggest that the social contextual trends (e.g., urban flight, declining social capital) that began in the 1980s continue to date (Conger \& Elder, 2000; Crockett, Shanahan, \& Jackson-Newsom, 2000). Given the overall decline of prosocial behaviors in the present sample, research is needed to determine whether this decline is associated with detrimental changes in the demographic characteristics of rural communities. Second, sample attrition resulted in a somewhat more select (i.e., better adjusted) sample by grades 10-12. However, the somewhat better adjusted sample at Time 4 could mean that the overall decline in prosocial behaviors observed in this study might be underestimated. Third, the data were based on the adolescent's perceptions of the quality of their parent and peer relationships and their own prosocial behaviors; thus, the estimates could be biased by the reliance on adolescents' self-reports. Future research using multiple measurement approaches is recommended. And fourth, there were some possible limitations regarding the measure of quality of peer relationships and the measure of prosocial behavior. Some researchers have noted that helping might differ as a function of the target of helping (Berndt, 1985) and also as a function of the type of prosocial behavior (Carlo $\&$ Randall, 2002). Further research on these possibilities is warranted.

\section{Summary and Conclusion}

The findings add to the sparse literature on change and stability of pro-social behaviors in adolescence with a sample of rural youth. The study showed an overall decline in prosocial behaviors from early to middle adolescence with a slight rebound in late high school. At the same time, there was remarkable stability in individual differences in prosocial behaviors across adolescence. For girls, but not boys, the change in prosocial behaviors was associated with changes in the quality of peer relationships. These findings suggest the need for future research designed to understand other sources of continuity and change in prosocial behaviors and to examine prosocial development during the transition to adulthood. Furthermore, although prior research on parenting 
and peer intervention programs suggest that changes in parenting and peers impact adolescent social competence (The Consortium on the School-Based Promotion of Social Competence, 1994), further research on possible bi-directional effects would help discern whether there are feedback effects from engaging in prosocial behaviors that impact the quality of parent and peer relationships. Such research would have important implications for intervention programs designed to promote positive social behaviors in adolescence.

\section{ACKNOWLEDGMENTS}

This research was funded by grant \#APR 000933-01 and contract 282-90-0047 from the Office of Adolescent Pregnancy Programs to Judith R. Vicary and by seed grants to Lisa Crockett and Judith Vicary from the College of Health and Human Development and the Center for the Study of Child and Adolescent Development at the Pennsylvania State University. Support for preparation of the manuscript was provided by a research award from the American Psychological Association and John Templeton Foundation to Gustavo Carlo and from the UNL Gallup Research Center to Gustavo Carlo and Lisa Crockett. We gratefully acknowledge the contributions of the participating schools and the project staff of the Rural Adolescent Development Study, with special thanks to Daphne Minner.

\section{REFERENCES}

Barnett, M. (1987). Empathy and related responses in children. In N. Eisenberg \& J. Strayer (Eds.), Empathy and its development (pp. 146-162). Cambridge, UK: Cambridge University Press.

Baumrind, D. (1991). The influence of parenting style on adolescent competence and substance abuse. Journal of Early Adolescence, 11, 56-95.

Berndt, T. J. (1985). Prosocial behaviors between friends in middle childhood and early adolescence. Journal of Early Adolescence, 5, 307-317.

Berndt, T. J., \& Ladd, G. W. (1989). Peer relationships in child development. New York: Wiley.

Beutel, A. M., \& Johnson, M. K. (2004). Gender and prosocial values during adolescence: A research note. Sociological Quarterly, 45, 379-393.

Bollen, K. A., \& Curran, P. J. (2004). Autoregressive latent trajectory (ALT) models: A synthesis of two traditions. Sociological Methods and Research, 32, 336-383.

Brown, B. B. (1989). The role of peer groups in adolescents' adjustment to secondary school. In T. J. Berndt \& G. W. Ladd (Eds.), Peer relationships in child development (pp. 188-216). New York: Wiley.

Bukowski, W. M., \& Sippola, L. K. (1996). Friendship and morality. In W. M. Bukowski \& A. F. Newcomb (Eds.), The company they keep: Friendship in childhood and adolescence (pp. 238-261). Cambridge, UK: Cambridge University Press.

Cairns, R. B., Cairns, B. D., Neckerman, H. J., Ferguson, L. L., \& Gariepy, J. (1989). Growth and aggression: 1. Childhood to early adolescence. Developmental Psychology, 25, 320-330. 
Carlo, G., Eisenberg, N., \& Knight, G. P. (1992). An objective measure of adolescents' prosocial moral reasoning. Journal of Research on Adolescence, 2, 331-349.

Carlo, G., Fabes, R. A., Laible, D., \& Kupanoff, K. (1999). Early adolescence and prosocial/ moral behavior II: The role of social and contextual influences. Journal of Early Adolescence, 19, 133-147.

Carlo, G., Koller, S. H., Eisenberg, N., Da Silva, M. S., \& Frohlich, C. B. (1996). A cross-national study on the relations among prosocial moral reasoning, gender role orientations, and prosocial behaviors. Developmental Psychology, 32, 231-240.

Carlo, G., Raffaelli, M., Laible, D. J., \& Meyer, K. A. (1999). Why are girls less physically aggressive than boys? Personality and parenting mediators of physical aggression. Sex Roles, 40, 711-729.

Carlo, G., \& Randall, B. A. (2002). The development of a measure of prosocial behaviors for late adolescents. Journal of Youth and Adolescence, 31, 31-44.

Carlo, G., Roesch, S. C., \& Melby, J. (1998). The multiplicative relations of parenting and temperament to prosocial and antisocial behaviors in adolescence. Journal of Early Adolescence, 18, 266-290.

Collins, L., Schafer, J. L., \& Kam, C. -M. (2001). A comparison of inclusive and restrictive strategies in modem missing data procedures. Psychological Methods, 6, 330-351.

Conger, R. D., \& Elder Jr., G. H. (2000). Children of the land: Adversity and success in rural America. Chicago: University of Chicago Press.

Crick, N. R., \& Gropeter, J. K. (1995). Relational aggression, gender, and social psychological adjustment. Child Development, 66, 710-722.

Crockett, L. J., \& Bingham, C. R. (2000). Anticipating adulthood: Expected timing of work and family transitions among rural youths. Journal of Research on Adolescence, 10, 151-172.

Crockett, L., Losoff, M., \& Petersen, A. C. (1984). Perceptions of the peer group and friendship in early adolescence. Journal of Early Adolescence, 4, 155-181.

Crockett, L. J., Shanahan, M. J., \& Jackson-Newsom, J. (2000). Rural youth: Ecological and life course perspectives. In R. Montemayor, G. R. Adams, \& T. P. Gullotta (Eds.), Adolescent diversity in ethnic, economic, and cultural contexts (pp. 43-74). Thousand Oaks, CA: Sage Publications.

Csikszenthmihalyi, M., \& Larson, R. (1984). Being adolescent: Conflict and growth in the teenage years. New York: Basic Books.

Curran, P. J. (2000). A latent curve framework for studying developmental trajectories of adolescent substance use. In J. Rose, L. Chassin, C. Presson, \& J. Sherman (Eds.), Multivariate Applications in Substance Use Research (pp 1-42). Hillsdale, NJ: Erlbaum.

Curran, P. J., \& Bollen, K. A. (2001). The best of both worlds: Combining autoregressive and latent curve models. In L. M. Collins \& A. G. Sayer (Eds.), New Methods for the Analysis of Change (pp. 107-135). Washington, DC: American Psychological Association.

Davis, M. H., \& Franzoi, S. (1991). Stability and change in adolescent self-consciousness and empathy. Journal of Research in Personality, 25, 70-87.

Dekovic, M., \& Janssens, J. M. A. M. (1992). Parents' child-rearing style and children's sociometric status. Developmental Psychology, 28, 925-932.

Duncan, S. C., Duncan, T. E., Alpert, A., \& Hops, H. (1997). Adolescent Alcohol Use Development and Young Adult Outcomes. Drug and Alcohol Dependence, 49, 39-48.

Duncan, T. D., Duncan, S. C., Strycker, L. A., Li, R, \& Alpert, A. (1999). An introduction to latent variable growth curve modeling: Concepts, issues, and applications. Mahwah, NJ: Erlbaum. 
Eberly, M. B., \& Montemayor, R. (1998). Doing good deeds: An examination of adolescent prosocial behavior in the context of parent/adolescent relationships. Journal of Early Adolescence, 13, 403-432.

Eberly, M. B., \& Montemayor, R. (1999). Adolescent affection and helpfulness toward parents: A 2-year follow-up. Journal of Early Adolescence, 19, 226-248.

Eisenberg, N., Carlo, G., Murphy, B., \& Van Court, P. (1995). Prosocial development in late adolescence: A longitudinal study. Child Development, 66, 911-936.

Eisenberg, N., \& Fabes, R. A. (1998). Prosocial development. In W. Damon (Series Ed.), N. Eisenberg (Vol. Ed.), Handbook of child psychology: Vol. 3. Social, emotional, and personality development (5th ed., pp. 701-778). New York: Wiley.

Eisenberg, N., Guthrie, I. K., Murphy, B. C., Shepard, S. A., Cumberland, A., \& Carlo, G. (1999). Consistency and development of prosocial dispositions: A longitudinal study. Child Development, 70, 1360-1372.

Eisenberg, N., Miller, P. A., Shell, R., McNalley, S., \& Shea, C. L. (1991). Prosocial development in adolescence: A longitudinal study. Developmental Psychology, 27, 849-857.

Eisenberg-Berg, N., \& Mussen, P. (1978). Empathy and moral development in adolescence. Developmental Psychology, 14, 185-186.

Enders, C. K. (2001). A primer on maximum-likelihood algorithms available for use with missing data. Structural Equation Modeling, 8, 128-141.

Estrada, P. (1995). Adolescents' self reports of prosocial responses to friends and acquaintances: The role of sympathy-related cognitive, affective, and motivational processes. Journal of Research on Adolescence, 5, 173-200.

Fabes, R. A., Carlo, G., Kupanoff, K., \& Laible, D. (1999). Early adolescence and prosocial/ moral behavior I: The role of individual processes. Journal of Early Adolescence, 19, 5-16.

Fan, X., \& Sivo, S. (2005). Sensitivity of fit indexes to misspecified structural or measurement model components: Rationale of two-index strategy revisited. Structural Equation Modeling, 12, 343-637.

Froming, W. J., Nasby, W., \& McManus, J. (1998). Prosocial self-schemas, self-awareness, and children's prosocial behavior. Journal of Personality and Social Psychology, 75, 766-777.

Furman, W., \& Masters, J. C. (1980). Affective consequences of social reinforcement, punishment, and neutral behavior. Developmental Psychology, 16, 100-104.

Garbarino, J. (1999). Lost boys: Why our sons turn violent and how we can save them. New York: Free Press.

Gilligan, C. (1982). In a different voice: Psychological theory and women's development. Cambridge, MA: Harvard University Press.

Grotevant, H. D. (1998). Adolescent development in family context. In W. Damon (Series Ed.), N. Eisenberg (Vol. Ed.), Handbook of child psychology, Vol. 3: Social, emotional, and personality development (5th ed., pp. 1097-1141). New York: Wiley.

Grusec, J. E. (1991). Socializing concern for others in the home. Developmental Psychology, 27, 338-342.

Grusec, J. E., \& Goodnow, J. J. (1994). Impact of parental discipline methods on the child's internalization of values: A reconceptualization of current points of view. Developmental Psychology, 30, 4-19.

Grusec, J. E., Goodnow, J. J., \& Cohen, L. (1996). Household work and the development of concern for others. Developmental Psychology, 32, 999-1007.

Gunnoe, M. L., Hetherington, E. M., \& Reiss, D. (1999). Parental religiosity, parenting style, and adolescent social responsibility. Journal of Early Adolescence, 19, 199-225. 
Hartup, W. W. (1983). Peer relations. In P. H. Mussen (Series Ed.), E. M. Hetherington (Vol. Ed.), Handbook of child psychology: Vol. 4 Socialization, personality, and social development (pp. 103-196). New York: Wiley.

Hill, J. P., \& Lynch, M. E. (1983). The intensification of gender-related role expectations during early adolescence. In J. Brooks-Gunn \& A. C. Petersen (Eds.), Girls at puberty: Biological and psychosocial perspectives (pp. 201-228). New York: Plenum Press.

Hoffman, M. L. (1983). Affective and cognitive processes in moral internalization. In E. T. Higgins, D. N. Ruble, \& W. W. Hartup (Eds.), Social cognition and development: A sociocultural perspective (pp. 236-274). Cambridge, UK: Cambridge University Press.

$\mathrm{Hu}, \mathrm{L}-\mathrm{T}$., \& Bentler, P. M. (1999). Cutoff criteria for fit indexes in covariance structure analysis: Conventional criteria versus new alternatives. Structural Equation Modeling, 6, 1-55.

Huesmann, L. R., Eron, L. D., Lefkowitz, M. M., \& Walder, L. 0. (1984). Stability of aggression over time and generations. Developmental Psychology, 20, 1220-1134.

Jacobson, K. C., \& Crockett, L. C. (2000). Parental monitoring and adolescent adjustment: An ecological perspective. Journal of Research on Adolescence, 10, 65-97.

Krevins, J., \& Gibbs, J. C. (1996). Parents use of inductive discipline: Relations to children's empathy and prosocial behavior. Child Development, 67, 3263-3277.

Lamborn, S. D., Mounts, N. S., Steinberg, L., \& Dornbusch, S. M. (1991). Patterns of competence and adjustment among adolescents from authoritative, authoritarian, indulgent, and neglectful families. Child Development, 62, 1049-1065.

Larson, R., \& Richards, M. H. (1991). Daily companionship in late childhood and early adolescence: Changing developmental contexts. Child Development, 62, 284-300.

Lefkowitz, E. S., Boone, T. L., Sigman, M., \& Kit-fong Au, T. (2002). He said, she said: Gender differences in mother-adolescent conversations about sexuality. Journal of Research on Adolescence, 12, 217-242.

Maccoby, E. E., \& Jacklin, C. N. (1974). The psychology of sex differences. Stanford, CA: Stanford University Press.

Maccoby, E. E., \& Martin, J. A. (1983). Socialization in the context of the family: Parent-child interaction. In E. M. Hetherington (Ed.), Handbook of child psychology: Vol. 4 Socialization, personality, and social development (pp. 1-101). New York: Wiley.

Marsh, H. W., Hau, K. T., \& Wen, Z. (2004). In search of golden rule: Comment on hypothesistesting approaches to setting cutoff values for fit indexes and dangers in over-generalizing $\mathrm{Hu}$ and Bentler's (1999) findings. Structural Equation Modeling, 11, 320-341.

Offer, D., Ostrov, E., \& Howard, K. I. (1981). The adolescent: A psychological self-portrait. New York: Basic Books Inc.

Petersen, A. C., Schulenberg, J. E., Abramowitz, R. M., Offer, D., \& Jarcho, H. D. (1984). A Self-image Questionnaire for Young Adolescents (SIQYA): Reliability and validity studies. Journal of Youth and Adolescence, 13, 93-111.

Pipher, M. (1994). Reviving Ophelia. New York: Grosset/Putnam.

Pulkinnen, L., \& Pitkanen, T. (1993). Continuities in aggressive behavior from childhood to adulthood. Aggressive Behavior, 19, 249-263.

Raykov, T. (2005). Analysis of longitudinal studies with missing data using covariance structure modeling with full-information maximum likelihood. Structural Equation Modeling, 12, 493-505.

Rice, K. G., \& Mulkeen, P. (1995). Relationships with parents and peers: A longitudinal study of adolescent intimacy. Journal of Adolescent Research, 10, 338-357.

Richards, M. H., Miller, B. V., O’Donnell, P. C, Wasserman, M. S., \& Colder, C. (2004). Parental monitoring mediates the effects of age and sex on problem behaviors among African Americans. Journal of Youth and Adolescence, 33, 221-233. 
Scales, P. C., Benson, P. L., Leffert, N., \& Biyth, D. A. (2000). Contribution of developmental assets to the prediction of thriving among adolescents. Applied Developmental Science, 4, 27-46.

Schafer, J. L., \& Graham, J. W. (2002). Missing data: Our view of the state of the art. Psychological Methods, 7, 147-177.

Schonert-Reichl, K. A. (1999). Moral reasoning during early adolescence: Links with peer group acceptance, friendship adjustment, and social behaviors. Journal of Early Adolescence, 19, 249-279.

Seginer, R., \& Somech, A. (2000). In the eyes of the beholder: How adolescents, teachers and school counselors construct adolescent images. Social Psychology of Education, 4, 139-157.

Staub, E. (1978). Positive social behavior and morality: Social and personal influences (Vol. 1). New York: Academic.

Steinberg, L., Lamborn, S., Darling, N., Mounts, N., \& Dornbusch, S. (1994). Over-time changes in adjustment and competence among adolescents from authoritative, authoritarian, indulgent, and neglectful families. Child Development, 65, 754-770.

Swisher, J. D., Shute, R. E., \& Bibeau, D. (1984). Assessing drug and alcohol abuse: An instrument for planning and evaluation. Measurement and Evaluation in Counseling and Development, 17, 91-97.

The Consortium on the School-Based Promotion of Social Competence. (1994). The schoolbased promotion of social competence: Theory, research, practice, and policy. In R. J. Haggerty, L. R. Sherrod, N. Garmezy, \& M. Rutter (Eds.), Stress, risk, and resiliency in children and adolescents: Processes, mechanisms, and interventions (pp. 268-316). Cambridge, UK: Cambridge University Press.

Vicary, J. R. (1991). Psychological impact of pregnancy on rural adolescents. Final report to the Office of Adolescent Pregnancy Programs for grant No. APR 000933-01, Contract No. 282-90-0047.

Wentzel, K. R., \& Asher, S. R. (1995). The academic lives of neglected, rejected, popular, and controversial children. Child Development, 66, 754-763.

Youniss, J. (1980). Parents and peers in social development: A sullivan-piaget perspective. Chicago: University of Chicago Press. 